\title{
Computational Drug Simulation: A step to the possible cure of COVID-19
}

\author{
Kumar Sharp ${ }^{1 *}$, Dr. Shubhangi Dange ${ }^{2}$
}

\begin{abstract}
${ }^{1} 2^{\text {nd }}$ MBBS undergraduate student, Government Medical College and Hospital, Jalgaon
${ }^{2}$ Associate Professor, Dept. of Microbiology, Government Medical College and Hospital, Jalgaon
\end{abstract}

*Corresponding author: -

Kumar Sharp

$2^{\text {nd }}$ MBBS undergraduate student,

Government Medical College and Hospital, Jalgaon

Email: ksharp0016@gmail.com

\begin{abstract}
World Health Organization declared COVID-19 as a pandemic on $11^{\text {th }}$ March,2020.

Without any exact cure or vaccine, this disease has certainly taken a toll of humanity. Computer-aided Drug Design (CADD) is the modern era simulator for aiding in finding cure before starting actual clinical trials in patients. We have not indulged into making a new drug but analysing the existing drugs as approved by FDA to find the possible cure options. Based on the above data from our study, we find that anti-inflammatory drugs like prednisone and anti-psychotic drugs can be used for targeting the spike glycoprotein of the SARS-CoV2 virus.

Keywords: COVID-19; CADD; FDA; Spike glycoprotein; Anti-inflammatory; Anti-psychotic
\end{abstract}

\section{Introduction}

World Health Organization declared COVID-19 as a pandemic on $11^{\text {th }}$ March,2020. As of writing this paper, 5,71,678 are infected and 26,494 dead globally ${ }^{[1]}$. India has 867 positive cases with 25 dead because of it ${ }^{[2]}$. Without any exact cure or vaccine, this disease has certainly taken a toll of humanity. Discovery of new drugs takes a lot of time and in times like these, a cure to be found first is essential. The organism causing this disease, SARS-CoV2, has been extensively mapped for its structure.

Computer-aided Drug Design (CADD) is the modern era simulator for aiding in finding cure before starting actual clinical trials in patients. This significantly reduces drug designing time which usually takes around $10-14$ years ${ }^{[3]}$. Bioinformatics which deals with CADD is a vast entity with enormous expandability. Of the various methods given in Nature by S Ou-Yang et al. ${ }^{[4]}$ we have used the Receptor-Ligand docking interaction. Receptor being the target protein and ligand being the drug which we intend to bind to it. We have not indulged into making a new drug but analysing the existing drugs as approved by FDA to find the possible cure options. 


\section{Methodology}

For our study we have included one protein structures from SARS-CoV2: Spike Glycoprotein 6VSB. This protein structure was downloaded from the protein databank website RCSPDB in (.pdb) format ${ }^{[5]}$. The 661 FDA approved drug structures were downloaded in(.sdf) format from ZINC15 docking website. The two websites used above are highly recommended for academia.

The software used for the study are PyRx, a virtual screening tool by MGLTools Scripps Edu. It includes Autodock Vina by MGLTools Scripps Edu [6]. Open Babel by Open Babel Development team was also used ${ }^{[7]}$. Molecular dynamics were visualized using PyMOL by DeLano Scientific LLC ${ }^{[8]}$.

\section{Steps:}

The protein structure was simulated upon in PyRx. The molecule in .pdb format was loaded and converted to Autodock macromolecule. The .sdf file containing the drug structures were loaded in PyRx using Open Babel which is included within it. The drugs were all then minimized to lowest energy configuration possible by Open Babel. Lowest energy configuration is necessary to reduce the overall potential energy of the ligand. It helps attain a conformation with lower delta $G$ values so as to be considered close to biological system ${ }^{[9]}$. Autodock Vina was then used for simulating the receptor-ligand binding with default force field parameters and the Vina Search Space parameters at:

Center X:225.612 Y:226.527 Z:224.3994

Dimensions (Angstrom) X:25.0000 Y:25.0000 Z:25.0000

Maximization of the search space returned errors because of limit capacity of 8 CPU cores. Results were generated at the end of docking which took about $20 \mathrm{hrs}$. Results were analysed on the basis of binding affinity and top 5 drug simulations were chosen in order of their decreasing binding affinity $(\mathrm{kcal} / \mathrm{mol})$. The potential drugs from the result were then analysed for ADME (Absorption, Distribution, Metabolism, Excretion) using the Swiss ADME database available on their website ${ }^{[10]}$. 


\section{Results}

The first table shows the binding affinity results for FDA approved drugs (total-638) when docked with 6VSB protein. Top 10 drugs are shown in increasing order of Binding affinity (Table 1).

\begin{tabular}{|l|l|l|l|}
\hline S.no. & Name of drug & ZINC15 ID & Binding Affinity (kcal/mol) \\
\hline $\mathbf{1}$ & Inapsine & 19796080 & -9.4 \\
\hline $\mathbf{2}$ & Ventavis & 100052688 & -9.4 \\
\hline $\mathbf{3}$ & Isavuconazole & 1485935 & -9.2 \\
\hline $\mathbf{4}$ & Prednisone & 3875357 & -9.1 \\
\hline $\mathbf{5}$ & Haloperidol & 537822 & -8.8 \\
\hline $\mathbf{6}$ & Butenafine & 1530975 & -8.8 \\
\hline $\mathbf{7}$ & Risperdal & 538312 & -8.7 \\
\hline $\mathbf{8}$ & Vilazodone & 1542113 & -8.7 \\
\hline $\mathbf{9}$ & Balsalazide & 3952881 & -8.7 \\
\hline $\mathbf{1 0}$ & Deflazacort & 4212809 & -8.7 \\
\hline
\end{tabular}

Table 1: 6VSB-FDA drugs binding affinity (Top 10)

Swiss ADME webtool results were compiled for the above 10 drugs (Table 1 ) in the following table as follows (Table 2).

\begin{tabular}{|l|l|l|l|l|l|l|l|}
$\begin{array}{l}\text { S.no. } \\
\text { (figure } \\
\text { no.) }\end{array}$ & Drug & $\begin{array}{l}\text { GI } \\
\text { absorption }\end{array}$ & $\begin{array}{l}\text { BBB } \\
\text { permeant }\end{array}$ & $\begin{array}{l}\text { ME } \\
\text { inhibitor }\end{array}$ & $\begin{array}{l}\text { Structure } \\
\text { similarity }\end{array}$ & Drug Target & Clinical uses \\
\hline $\mathbf{1}$ & Inapsine & Yes & Yes & Yes & Droperidol & $\begin{array}{l}\text { Muscarinic } \\
\text { acetylcholine } \\
\text { receptor M4 }\end{array}$ & Sedative \\
\hline [GPCR]
\end{tabular}




\begin{tabular}{|l|l|l|l|l|l|l|l|l|}
\hline $\mathbf{8}$ & Vilazodone & Yes & No & Yes & Vilazodone & $\begin{array}{l}\text { Serotonin 1b } \\
\text { HT1b) } \\
\text { Receptor [GPCR] }\end{array}$ & Depression \\
\hline $\mathbf{9}$ & Balsalazide & Low & No & No & Balsalazide & $\begin{array}{l}\text { Caspase [protease] } \\
\text { Ulcerative } \\
\text { colitis }\end{array}$ \\
\hline $\mathbf{1 0}$ & Deflazacort & Yes & No & No & Ciclesonide & $\begin{array}{l}\text { Mu opioid } \\
\text { receptor [GPCR] }\end{array}$ & $\begin{array}{l}\text { Anti- } \\
\text { inflammatory }\end{array}$ \\
\hline
\end{tabular}

Data compiled from Swiss ADME webtool. GI means Gastrointestinal. BBB means Blood Brain Barrier. ME means Microsomal Enzyme. GPCR means G-protein coupled receptor.

Table 2: SWISS ADME drug data compilation

\section{Discussion}

On the basis for our study, anti-inflammatory drugs like prednisone and anti-psychotic drugs like haloperidol and Risperdal are potential drug candidates. A study on 138 hospitalized patients with 2019 novel coronavirus-infected pneumonia in Wuhan, China showed use of glucocorticoid therapy in $44.9 \%$ cases ${ }^{[11]}$. Another comparative study between old and young adults infected with coronavirus and other illness shows prednisone was more commonly used in older individuals but reasons for use were not recorded [12]. Haloperidol and Risperdal were among the 64 drugs tested for inhibiting growth of SARS-CoV virus and their formulations were patented in the United States of America ${ }^{[13]}$. These drugs are also easily available in government hospital setup and hence are not difficult to administer in times of global pandemic. Computer-aided drug designing can definitely speed-up drug analysis but has some limitations like technical limitation, lack of quality datasets, lack of ability to asses multi-drug effects, model interpretation issues among others ${ }^{[14]}$. Clinical trials are however mandatory before public use.

\section{Conclusion}

Based on the above data from our study, we find that anti-inflammatory drugs like prednisone can be used for targeting the spike glycoprotein of the SARS-CoV2 virus. This class of drugs can also decrease the hypersensitive immune reaction of body against the coronavirus which actually harms the patient's own respiratory system. Anti-psychotic drugs also are showing significant binding potential to spike glycoprotein. Clinical trials are mandatorily necessary for testing these drugs.

All necessary images of the articles are included under images heading.

\section{Supplementary material}

The above results for all 631-drug docking and the Swiss ADME data are uploaded on the following drive link for future reference and analysis:

https://drive.google.com/folderview?id=13bVUfmUi6azyUqcdrF Y8zUx21w66dhR 
Ethical consideration: Not Required

Source of funding: Not required

Conflict of Interest: None.

\section{Images:}

(Sources: PyMOL, PyRx, ZINC15)
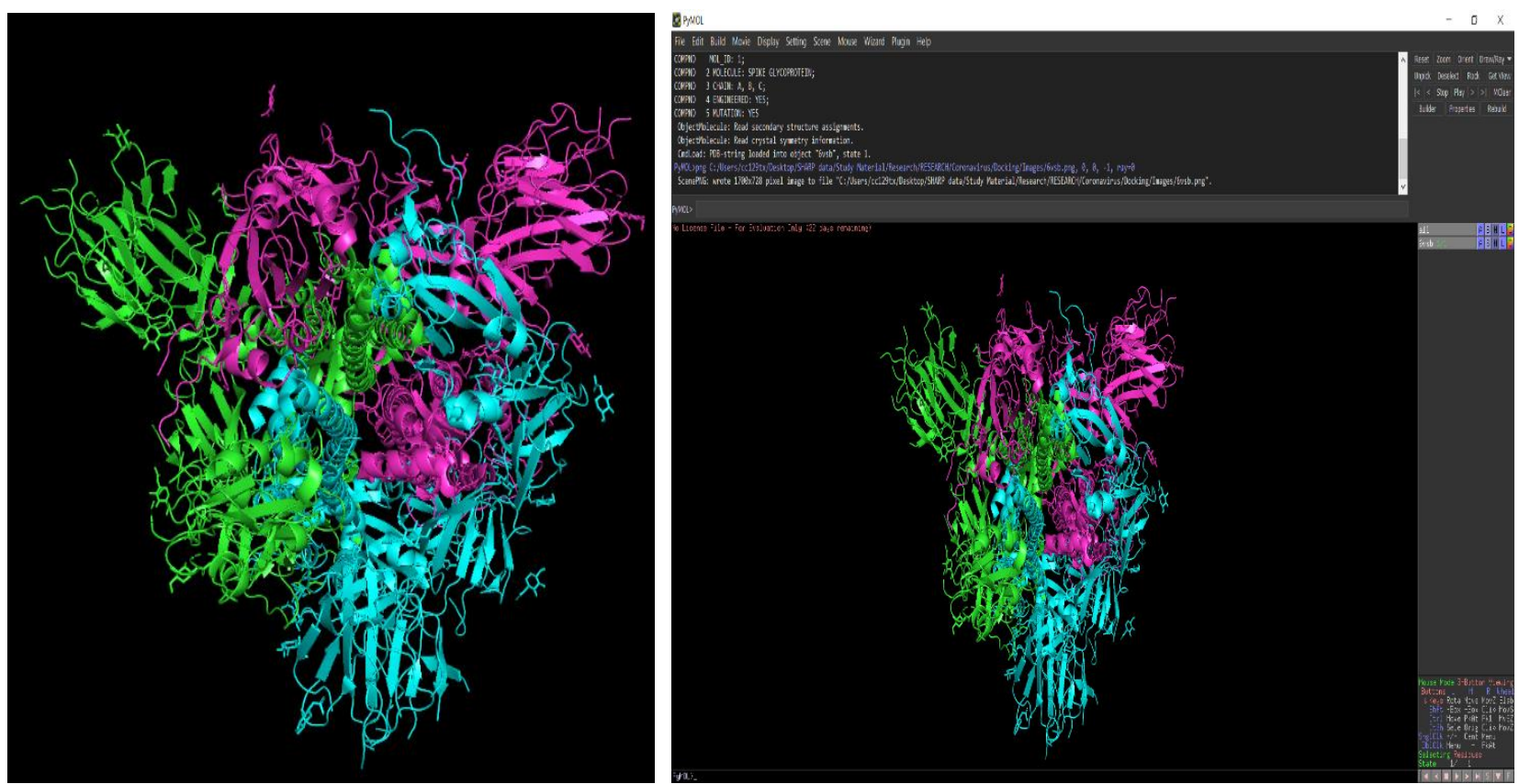

Figure 1: 6VSB spike glycoprotein.

Figure 2: Snapshot of PyMOL window. 


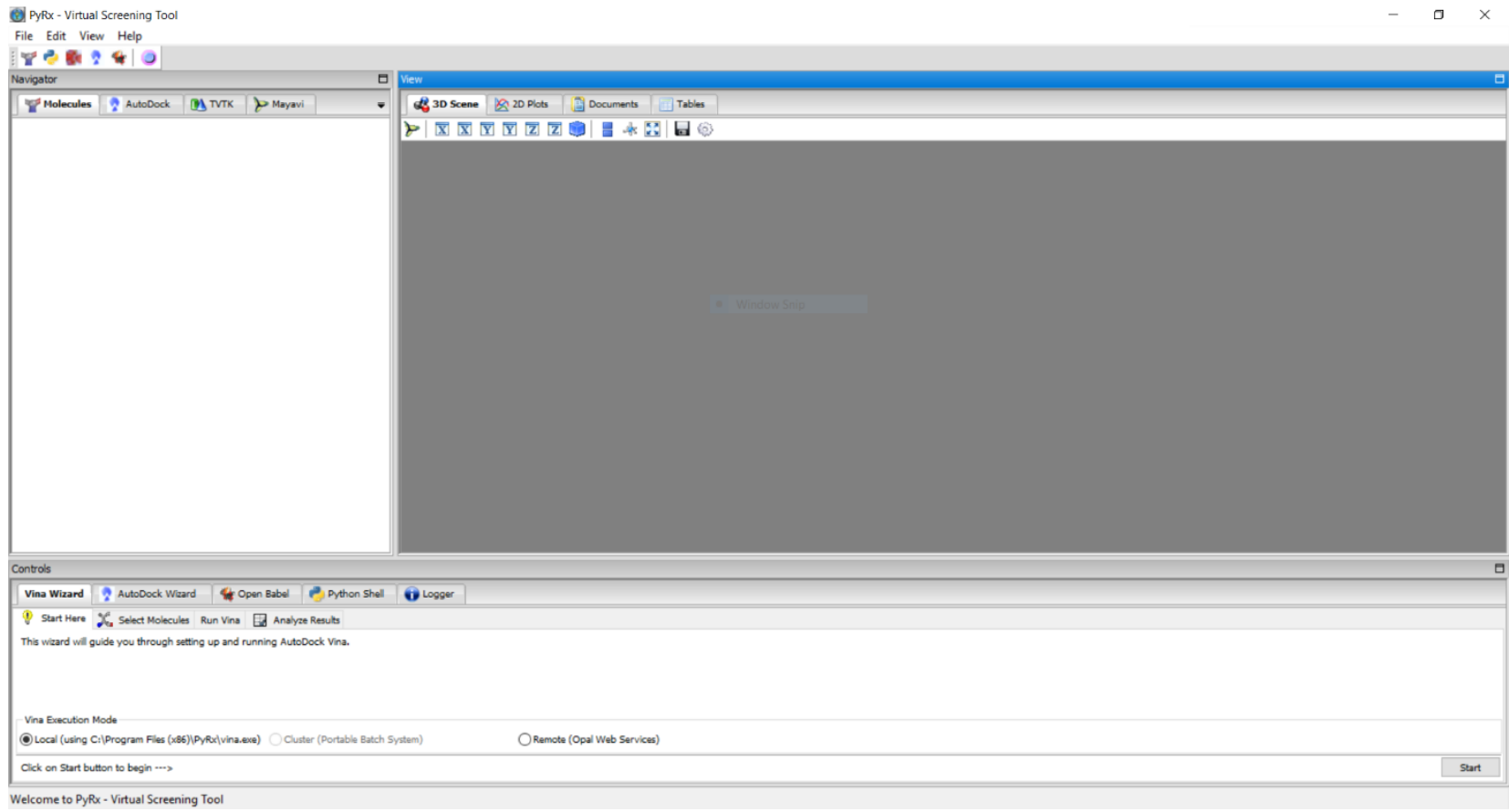

Figure 3: Snapshot of PyRx window (Autodock Vina and Open Babel included)
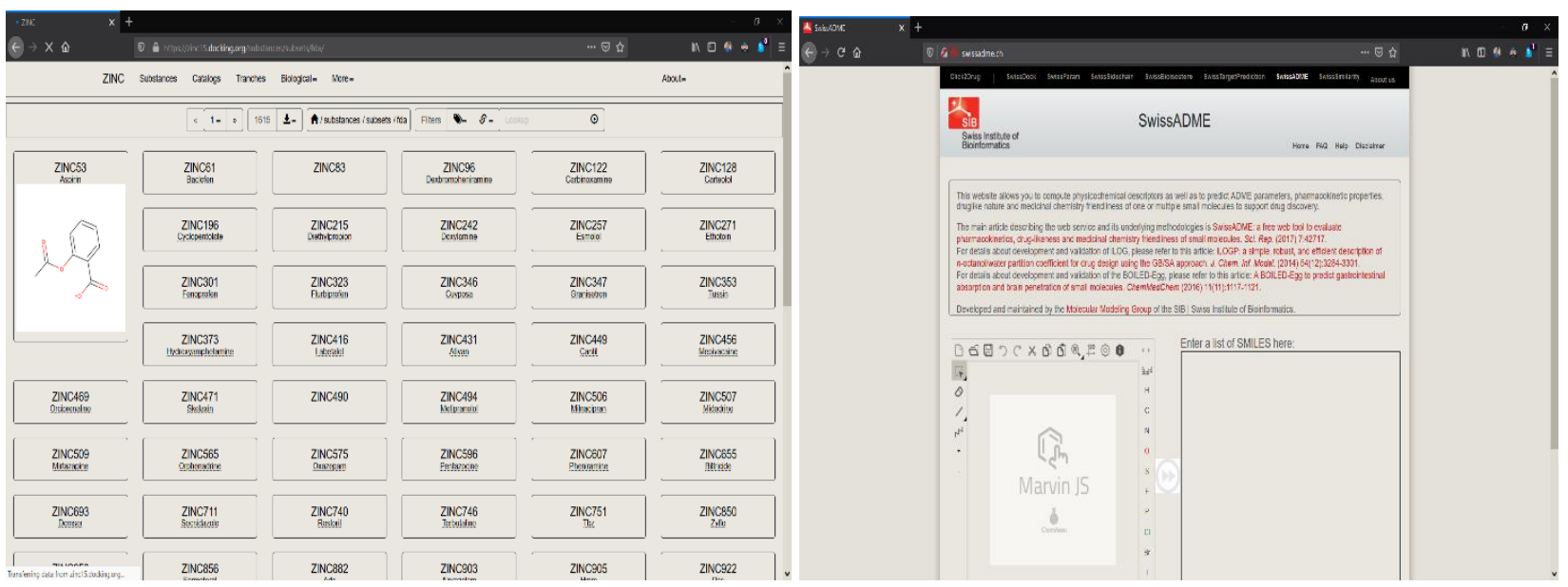

Figure 4: Snapshot of ZINC15 website

Figure 5: Snapshot of Swiss ADME website. 

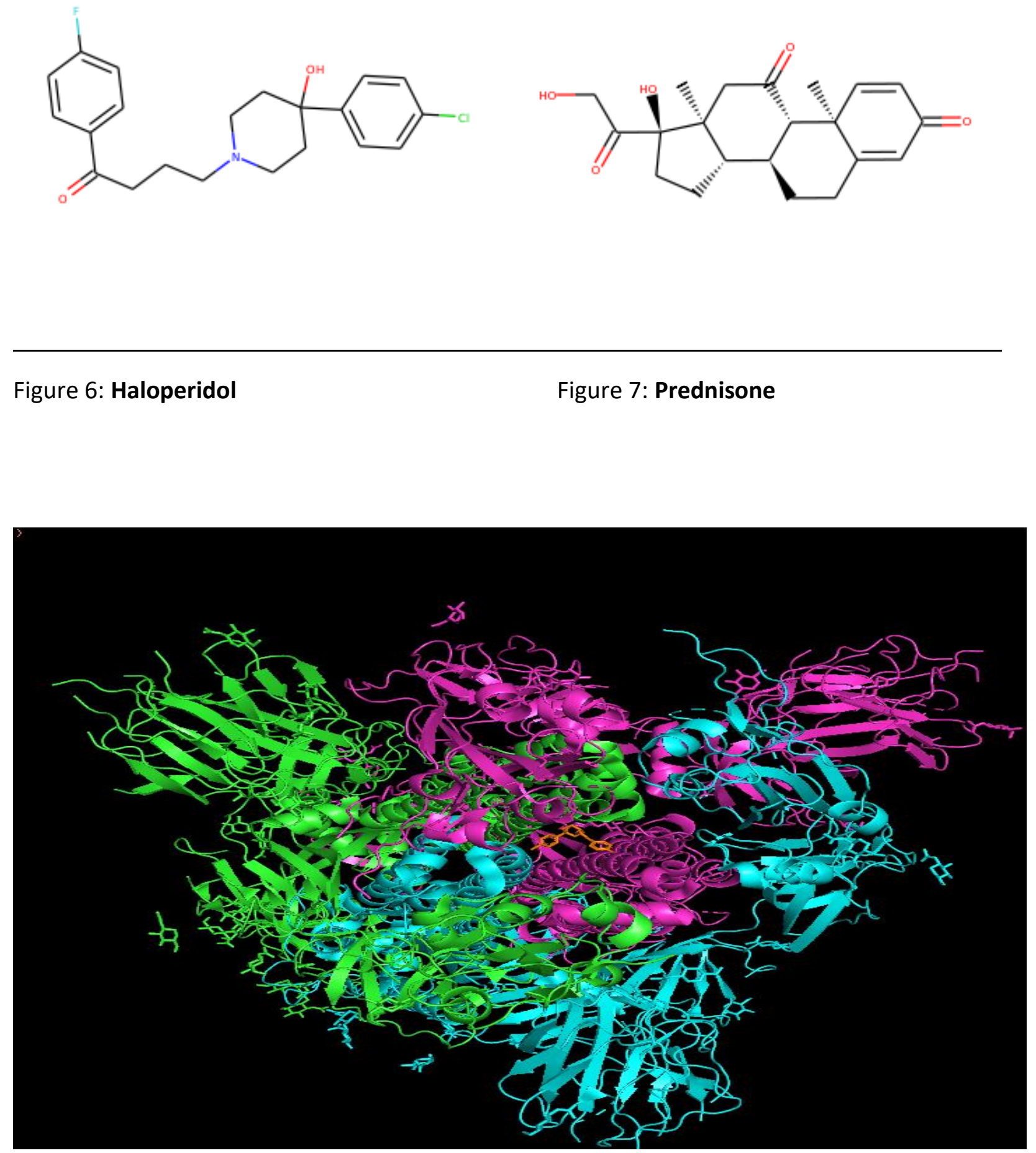

Figure 8: Haloperidol(orange) docked within 6VSB. PyMOL visualization. 


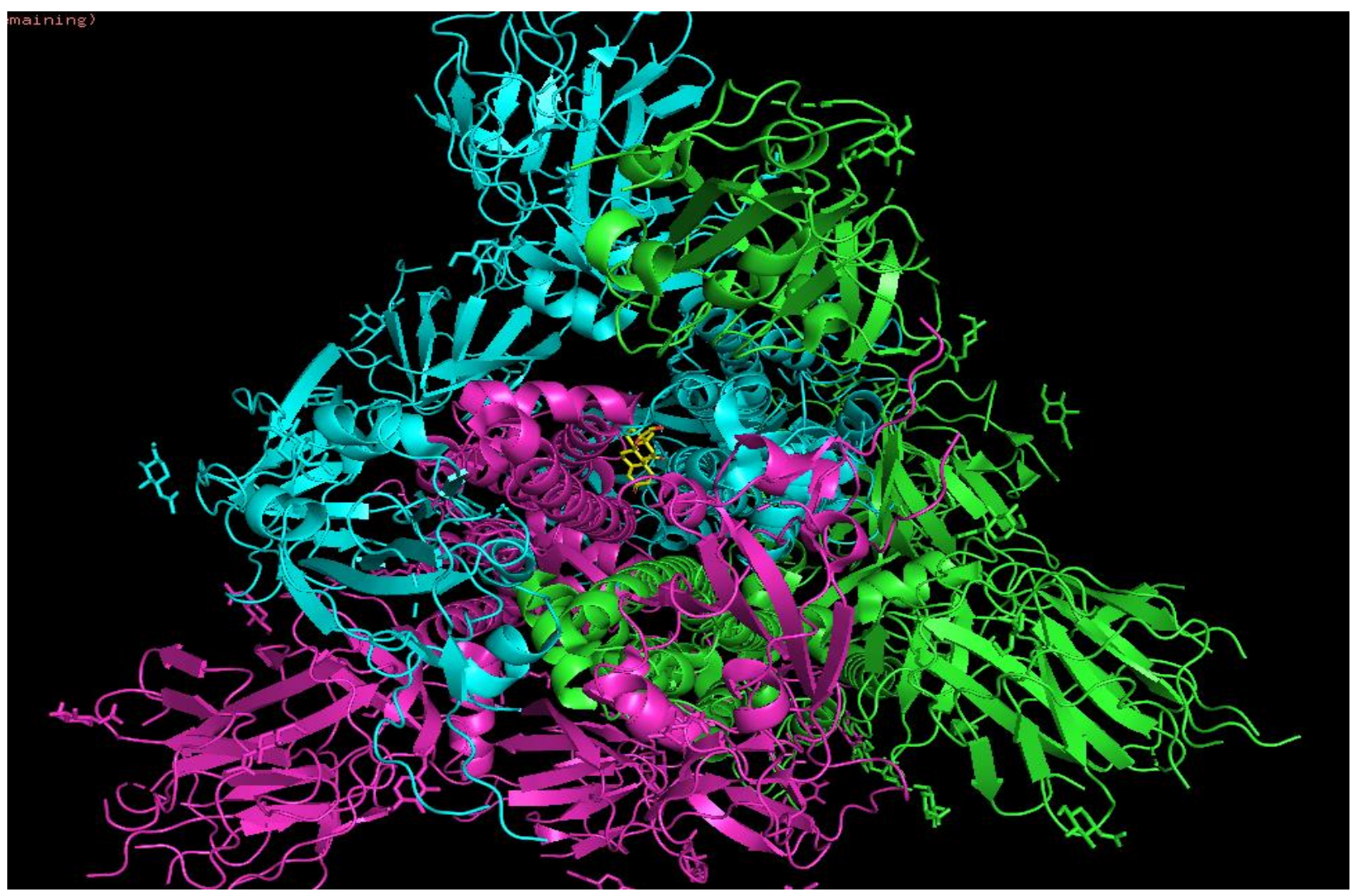

Figure 9: Prednisone(yellow) docked with 6VSB.PyMOL visualization.

\section{References:}

1. COVID-19 Situation Report 68: World Health Organization

2. Ministry of Health and Family Welfare, Government of India as of 29.03 .2020

3. Surabhi, Singh BK, Computer Aided Drug Design: An Overview, Journal of Drug Delivery and Therapeutics. 2018; 8(5):504-509

4. Si-sheng OU-YANG et al.: Computational drug discovery, Acta Pharmacologica Sinica (2012) 33: 1131-1140

5. www.rcsb.org RCSB PDB protein database Helen M. Berman, John Westbrook, Zukang Feng, Gary Gilliland, T. N. Bhat, Helge Weissig, Ilya N. Shindyalov, Philip E. Bourne, The Protein Data Bank, Nucleic Acids Research, Volume 28, Issue 1, 1 January 2000, Pages 235-242, https://doi.org/10.1093/nar/28.1.235

6. O. Trott, A. J. Olson, AutoDock Vina: improving the speed and accuracy of docking with a new scoring function, efficient optimization and multithreading, Journal of Computational Chemistry 31 (2010) 455-461

7. N M O'Boyle, M Banck, C A James, C Morley, T Vandermeersch, and G R Hutchison. "Open Babel: An open chemical toolbox." J. Cheminf. (2011), 3, 33. DOI:10.1186/1758-2946-3-33

8. The PyMOL Molecular Graphics System, Version 1.2r3pre, Schrödinger, LLC. 
9. Desai, Manan. (2015). Re: Is energy minimization after docking necessary before running analysis?

https://www.researchgate.net/post/Is_energy_minimization_after_docking_necessary_b efore_running_analysis/54e18c19d5a3f264338b4652/citation/download.

10. Daina, A. et al. SwissADME: a free web tool to evaluate pharmacokinetics, drug-likeness and medicinal chemistry friendliness of small molecules. Sci. Rep. 7, 42717; doi: 10.1038/srep42717 (2017)

11. Wang, Dawei et al. Clinical Characteristics of 138 Hospitalized Patients with 2019 Novel Coronavirus-infected Pneumonia in Wuhan, China. JAMA doi:10.1001/jama.2020.1585 (2020)

12. Geoffrey J. Gorse et al. Coronavirus and Other Respiratory Illnesses Comparing Older with Young adults. The American Journal of Medicine 2015 doi: 10.1016/j.amjmed.2015.05.034

13. Hsu et al. Treatment of Coronavirus Infection. United states Patent no.: US 7,544,712 B1

14. Ray Dr. Amit 7 limitations of Molecular Docking \& Computer Aided Drug Design and Discovery.AMITRAY.COM. 2018 Oct,21, https://amitray.com/7-limitations-of-moleculardocking-computer-aided-drug-design-and-discovery/ Accessed 01-Apr-2020 